\title{
Qual o Diagnóstico?
}

\section{APRESENTAÇÃO DO CASO}

Paciente do sexo masculino, 78 anos de idade, encaminhado para exame de Holter de 24 horas devido a queixas de cansaço por esforço e palpitação. A hipótese diagnóstica ou os antecedentes do paciente não foram referidos. O exame foi gravado em clínica privada e encaminhado digitalmente para análise em nosso serviço. Após tentativa de busca de informações clínicas, soubemos que o paciente é portador de marcapasso cardíaco; porém, sem nenhuma informação sobre o motivo ou a data do implante, a marca ou o modelo do gerador de pulso e tampouco a programação do dispositivo.

Resumidamente, a frequência mínima observada foi de 46 bpm, a máxima de 122 bpm, com frequência cardíaca média de $63 \mathrm{bpm}$. Foram observados 89 batimentos classificados como ectopias ventriculares isoladas. $\mathrm{O}$ gráfico de tendências mostra as curvas registradas. Os traçados abaixo são exemplos representativos da gravação.

Algumas perguntas: qual é o ritmo de base? Qual a provável programação do marcapasso? O sistema encontra-se normofuncionante? Há alguma anormalidade observada?

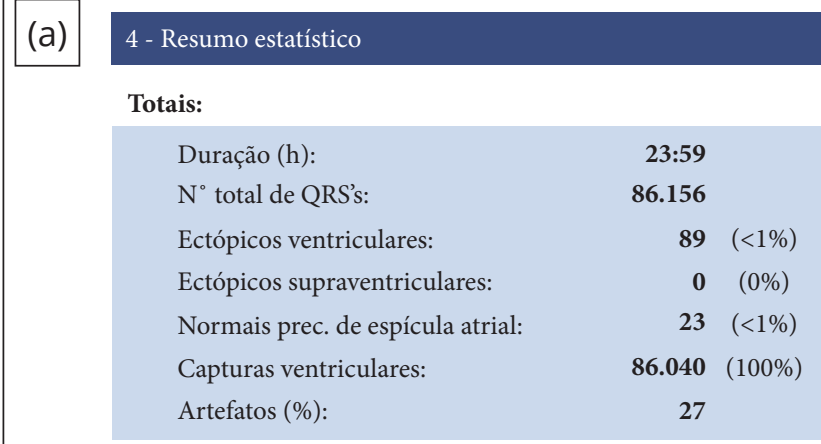

Arritmias ventriculares:
89 Isoladas, das quais
0 em 0 episódios de Bigeminismo
0 episódios em Pares
o Taquicardias

0 Isoladas

0 Pareadas

0 Taquicardias
Frequência cardíaca:

Mín: $\quad 46$ bpm às 04:56:40
Média: $\quad 63$ bpm
Máx: $\quad 122$ bpm às 06:59:56
F.C. $\geq$ 120bpm durante 00:00:34 h
F.C. $\leq$ 50bpm durante 00:00:44 h

Pausas

0 Pausas $(\geq 2,0$ s)

Depressão do ST
C1: 0 episódios
C2: 0 episódios
C3: 0 episódios

Elevação do ST

C1: 0 episódios

C2: 0 episódios

C3: 0 episódios

Figura 1. Resumo estatístico e gráfico de tendências dos eventos nas 24 horas do exame. 
Continuação...

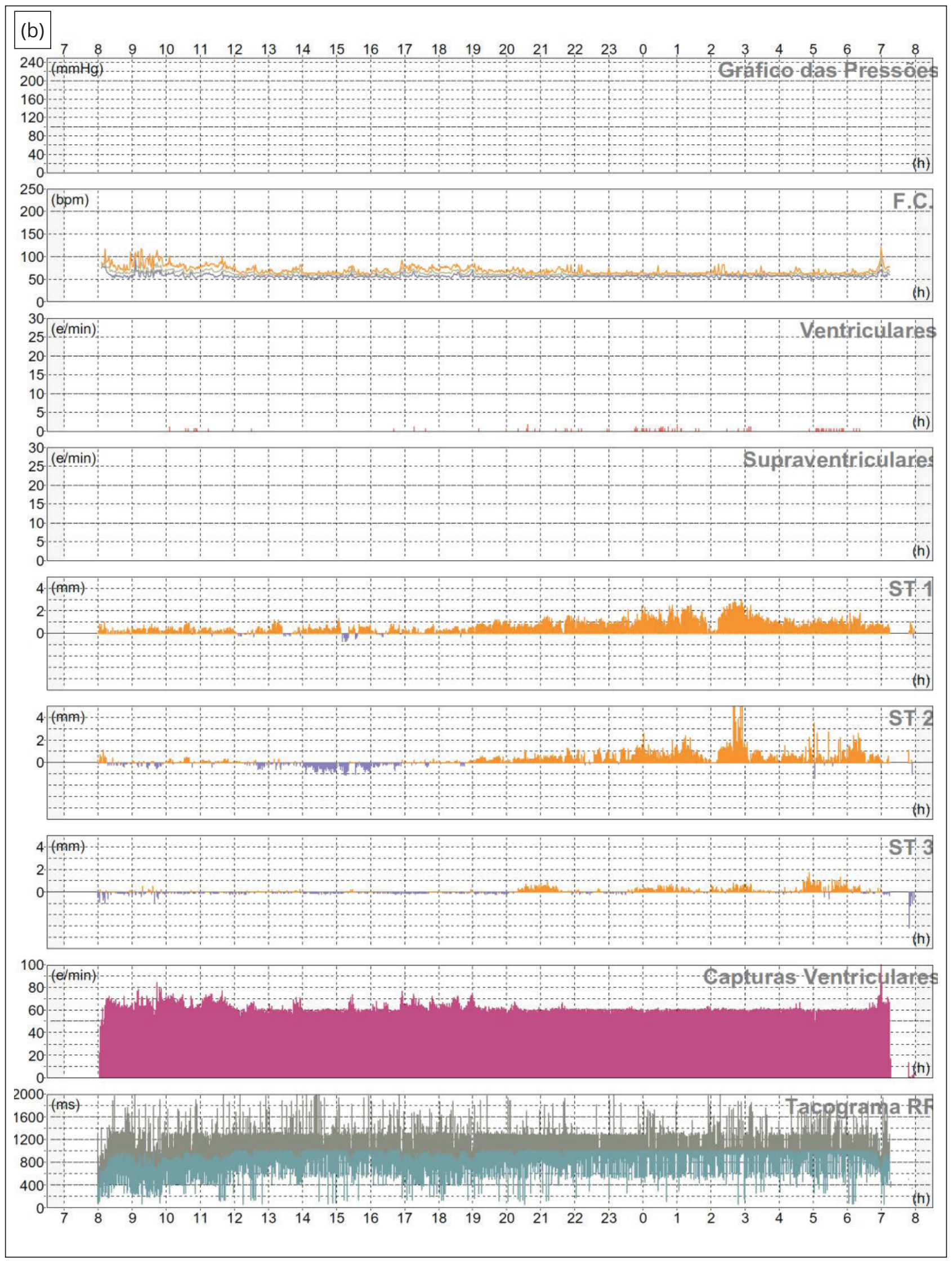

Figura 1. Resumo estatístico e gráfico de tendências dos eventos nas 24 horas do exame. 


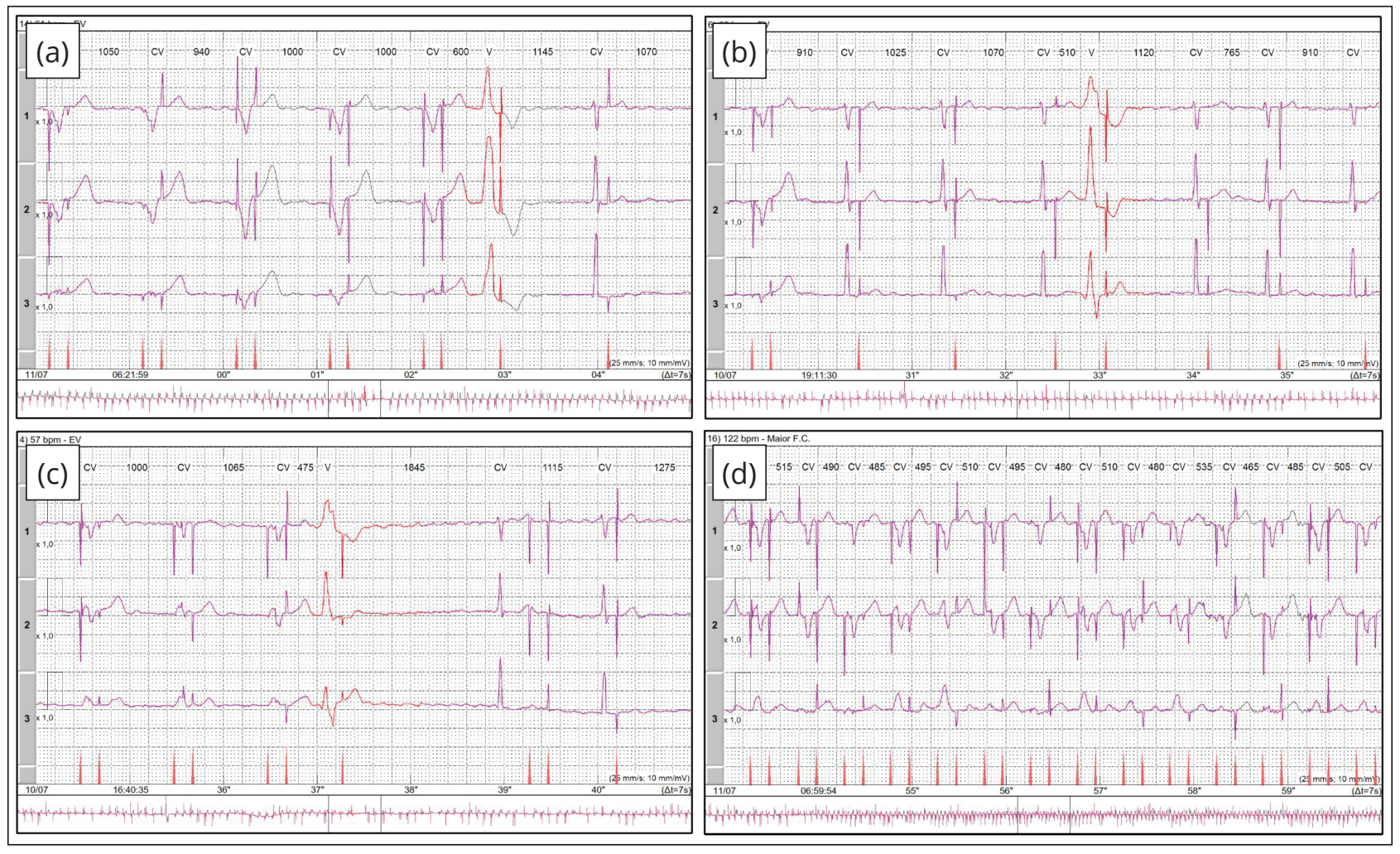

Figura 2. (a,b) Exemplos de traçados; (c) menor frequência cardíaca e (d) maior frequência cardíaca.

\section{DISCUSSÃO}

Apesar de ser altamente indesejável, analisar exames de Holter de 24 horas sem um mínimo de informações clínicas é infelizmente quase que a rotina no nosso meio. Quando se trata de paciente portador de marcapasso cardíaco, a falta de informações traz dificuldades adicionais, devido à imensa gama de possibilidade de programações e algoritmos específicos de cada marca e modelo de dispositivo, que prejudicam a interpretação eletrocardiográfica.

Vamos à análise do exame.

O gráfico de tendências (Fig. 1b) não sugere qualquer anormalidade, enquanto o resumo estatístico (Fig, 1a) mostra frequência cardíaca mínima de 46 bpm, relativamente incomum em pacientes portadores de marcapassos.

Os traçados mostram ritmo cardíaco associado à presença de duas espículas de marcapasso, melhor identificadas pelos marcadores em vermelho na base dos traçados, o que sugere tratar-se de marcapasso de câmara dupla. O intervalo médio entre os batimentos estimulados é de $1.000 \mathrm{~ms}$, sugerindo frequência mínima programada de $60 \mathrm{bpm}$. Observa-se que o intervalo entre as duas espículas é de $200 \mathrm{~ms}$.

O momento de maior frequência cardíaca (Fig. 2d) mostra que a elevação se deve à ação automática do marcapasso, sugerindo ativação de adaptação por biossensor. Tratando-se de marcapasso de câmara dupla, o modo provável da programação do caso deve ser DDDR.

A análise cuidadosa dos traçados mostra ainda ausência de ondas $\mathrm{P}$ e padrão de linha de base típica de fibrilação atrial.

No entanto, mais do que os fatos acima, um dado chama a atenção: após a primeira espícula do marcapasso, segue-se captura ventricular (QRS), sendo que a segunda espícula ocorre após a ativação elétrica ventricular (Figs. 2a-d). Ainda, na Fig. 2b, observa-se QRS espontâneo seguido de espícula de marcapasso, sem captura aparente de atividade elétrica biológica.

O mesmo ocorre após ectopias ventriculares sinalizadas como QRS alargados, em vermelho, com sinalização em V no topo dos traçados: extrassístoles ventriculares seguidas de espículas. 
O conjunto dos dados acima sugere fortemente que exista inversão da conexão dos cabos eletrodos ao gerador do marcapasso, com o eletrodo atrial conectado à saída ventricular e o eletrodo ventricular conectado à saída do gerador.

Dessa forma, a estimulação do canal atrial do marcapasso captura o ventrículo direito, gerando o QRS após a primeira espícula. Quando há QRS espontâneo, seja pela condução AV nativa, seja pela ectopia ventricular, o marcapasso sente tal atividade e deflagra estimulação (VAT), transmitida erroneamente ao átrio direito devido à troca inadvertida da posição dos eletrodos (Figs. 2a-c)

Com a inversão da conexão dos eletrodos, a presença da fibrilação atrial poderia inibir completamente a emissão de espículas ventriculares do marcapasso. Dois fatores, no entanto, justificam que esse fato tenha sido detectado somente em raros momentos da gravação (Fig. 2c): o primeiro é que geralmente a amplitude das ondas $\mathrm{F}$ do átrio em fibrilação costuma ser de baixa amplitude e o segundo é que a sensibilidade nominal do canal ventricular dos marcapassos costuma ser mais alta do que a sensibilidade atrial.

Concluindo, o laudo emitido foi o seguinte:

1. Ritmo de fibrilação atrial, com baixa resposta ventricular.

2. Presença de atividade de marcapasso cardíaco de estimulação atrioventricular e adaptação automática da frequência cardíaca por biossensor, modo DDDR, frequência de base programada em 60 ppm e frequência máxima registrada de 122 bpm, com frequência média de 63 bpm.

3. Há sinais sugestivos de inversão na conexão dos cabos eletrodos ao gerador do marcapasso, com o eletrodo atrial conectado à conexão ventricular e o eletrodo ventricular à conexão atrial do gerador. Com a emissão da primeira espícula pelo marcapasso, há captura inadvertida do ventrículo direito, seguida da emissão da segunda espícula, após $200 \mathrm{~ms}$ do intervalo AV.

4. Ectopia ventricular rara, com ocorrência de 89 extrassístoles ventriculares isoladas.

5. Curtos e raros momentos de inibição da estimulação cardíaca pela deteç̧ão da atividade elétrica da fibrilação ventricular pelo canal ventricular do marcapasso, gerando maior intervalo $\mathrm{R}-\mathrm{R}$ de $1,8 \mathrm{~s}$.

O clínico do paciente foi informado imediatamente da conclusão do exame para que adotasse as medidas necessárias para a correção do problema.

\title{
CONCLUSÃO
}

Os autores descrevem os aspectos eletrocardiográficos encontrados em Holter de 24 horas de paciente com conexão inadvertida dos cabos eletrodos ao gerador de marcapasso de câmara dupla.

\section{AUTORES}

\author{
Eduardo Rodrigues Bento Costa ${ }^{1, *}$, Vagner Rossato Pegoraro ${ }^{1}$, Andreza Chaguri Vellenich ${ }^{1}$ \\ Costa ERB (D) https://orcid.org/0000-0002-3342-5369 \\ Pegoraro VR (D) https://orcid.org/0000-0003-3448-320X
}

1.CardioRitmo - São José dos Campos (SP) - Brasil

*Autor correspondente: educosta.cardiol@uol.com.br 